\title{
How many reservoirs? An analysis of flow recessions from a glacier basin
}

\author{
ANGela M. GURNELL \\ GeoData Institute and Department of Geography, University of Southampton, Southampton SO9 5NH, England
}

\begin{abstract}
Analysis of hydrograph-recession curves from temperate catchments has frequently been directed towards identifying a linear-storage element with mean residence time $K$ which characterizes the delayed-flow component. This paper presents the results of applying such an analysis to recession curves from 11 years of discharge records from a glacier basin. Four reservoirs are identified but their estimated recession coefficients ( $K$ values) are found to vary with discharge and with time in the ablation season. This implies that the reservoirs are non-linear. Whilst it may be helpful for the interpretation of glacier-hydrological processes to identify several reservoirs, it appears that a single non-linear reservoir may provide an adequate representation of the glacier for operational forecasting purposes.
\end{abstract}

\section{INTRODUGTION}

Analysis of hydrograph-recession curves from temperate catchments has frequently been directed towards identifying a linear-storage element with mean residence time $K$ which characterizes the delayed-flow component (e.g. Barnes, 1939; Bako and Owoade, 1988; Nathan and McMahon, 1990). Such an approach assumes that recession flows represent outflow from a linear reservoir and that, during periods when there is no recharge to the reservoir, the outflow $\left(Q_{t}\right)$ at time $t$ can be expressed as a function of a preceding recession flow $\left(Q_{0}\right)$ at time $t_{0}$ and the storage constant $K$ :

$$
Q_{t}=Q_{0} \exp \left(-\left(t-t_{0}\right) / K\right) .
$$

This implies that during periods of recession flow, the value of $K$ can be estimated from the slope of a semilogarithmic plot of discharge against time, where recessions that conform to outflows from a linear reservoir will plot as straight lines.

In glacier basins, linear reservoirs have often been employed in modelling outflow hydrographs. For example, Lundquist's (1982) operational hydrological model for estimating meltwater production from air-temperature data employs two parallel linear reservoirs (a "fast" and a "slow" reservoir) to translate the estimated meltwater input from different altitudinal zones into the outflow hydrograph from the entire glacier basin. In contrast, Oerter and others (1981) and Baker and others (1982) employed four linear reservoirs, which they described as parallel, although some are linked in series in their run-off model, to translate estimates of ice- and snow-meltwater (based on meteorological observations) and ground water, from different locations within the basin of Vernagtferner glacier, into a combined outflow hydrograph. They were able to separate the four reservoirs by arguing that the recession from the fastest reservoir corresponded to the initial recession of the falling limb of the diurnal discharge hydrograph because such recession (of ice-meltwater) would be from a reservoir that was receiving no input once ice ablation ceased at night. In this way, they were able to identify $K$ values for the faster reservoirs, in addition to the more commonly derived estimates of longer-term recession coefficients from slower reservoirs, that can be identified during summer snowfall events (e.g. Collins, 1982).

Semi-logarithmic plots of discharge against time during recession flows frequently reveal breaks of slope between apparently linear components of the plotted curve. Such breaks of slope can be interpreted as being the breaks in recession between different reservoirs. $K$ values estimated in such cases represent aggregates of the combined recessions of all reservoirs that are contributing to the plotted curve. Reservoir-specific $K$ values can only be estimated if the recessions from each reservoir can be separated. Such a separation is relatively straightforward if the reservoirs are parallel, since a linear extension of the slower recession can be employed to separate the faster, superimposed recession. However, if the reservoirs are connected partly or entirely in series, separation is problematic because recharge may be occurring in one or both reservoirs, so invalidating the application of Equation (1) and throwing doubt on the validity of a linear separation between the two reservoirs on a semilogarithmic plot. These problems will be most marked when dealing with rapidly responding reservoirs. Ideally, corroborating evidence is required to achieve a valid separation and thus a valid independent estimate of $K$ for each reservoir. For example, Oerter and others (1981) presented evidence from tracer experiments and "groundwater" levels in the firn aquifer of Vernagtferner glacier to corroborate their separations. From their analyses, they suggested that an average residence time ( $K$ value) of $4 \mathrm{~h}$ is appropriate for their ice-melt reservoir; $30 \mathrm{~h}$ for 
snowmelt running directly on to ice; $430 \mathrm{~h}$ for snow and firn melt from high firn areas where there is significant storage of water within the firn; and an infinitely longstorage coefficient for the ground-water reservoir.

As part of an integrated study of the glacial hydrology of Haut Arolla glacier basin (Valais, Switzerland), flow records were inspected in order to identify recession flows and to estimate the number of linear reservoirs that appeared to be operating and their respective storage $(K)$ coefficients. This paper merely presents the analysis of these recession flows and the associated estimated $K$ values. Because the analysis is based entirely on recession flows, there is only a preliminary attempt to separate flows from different reservoirs. Breaks of slope between linear components of semi-logarithmic plots have been used to identify the number of linear reservoirs that appear to be operating and the slopes of the linear sections of the plots have been used to estimate accumulated or aggregated values of $K$ for each of the reservoirs identified. A first estimate of separated $K$ values is then derived using linear separation where two adjacent linear components are identified on semi-logarithmic plots of recessions. The pattern in the estimated aggregated and separated $K$ values is investigated and is related both to the timing of the recession and to the associated discharge levels. Subsequent papers will report the evidence for defining and separating reservoirs that is provided by concurrent chemical analyses of the meltwater and dye-tracer studies. Such evidence will aid in the interpretation of the number and location of hydrological reservoirs within the basin and whether they are parallel or serial, as well as underpinning separation of recession flows. The evidence presented in this paper from analysis of recession flows indicates that the glacier hydrology could equally well be represented by four linear reservoirs or one non-linear reservoir, or an intervening number of reservoirs of linear, or non-linear form depending on the purpose of the study.

\section{DATA PREPARATION AND ANALYSIS}

Discharge from the basin of Haut Glacier d'Arolla, Valais, Switzerland, is monitored by Grande Dixence S.A. at a rectangular weir structure located approximately $1 \mathrm{~km}$ from the glacier snout. The discharge records from this station that are analysed here are hourly mean flows. The basin has an area of $11.7 \mathrm{~km}^{2}$, of which approximately $6.3 \mathrm{~km}^{2}$ is covered by permanent snow and ice. The basin has an elevation range of $2560-3838 \mathrm{~m}$.

Ten years of discharge records (1 June-20 September 1978-87, inclusive) were inspected to find periods of prolonged $(>24 \mathrm{~h}$ ) recession flows. In addition, all simple (i.e. linear on semi-logarithmic plots) recessions during the 1989 ablation season (1 June-30 August, inclusive) were identified. A characteristic of diurnal-flow recessions in this basin is that a clear break of slope appears on many days, particularly when ablation is high (Fig. 1a), and that when a break of slope does not occur it is usually early in the ablation season and the recession appears to be similar to the lower-slope element of the dual recessions. Thus, the recessions were usually indexed using this lower-slope element as a starting point (labelled
Diurnal flow recessions

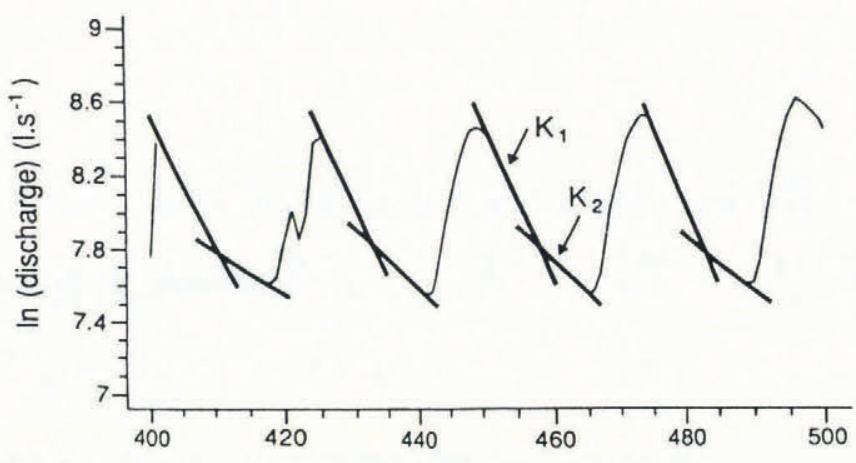

Longer-term recessions

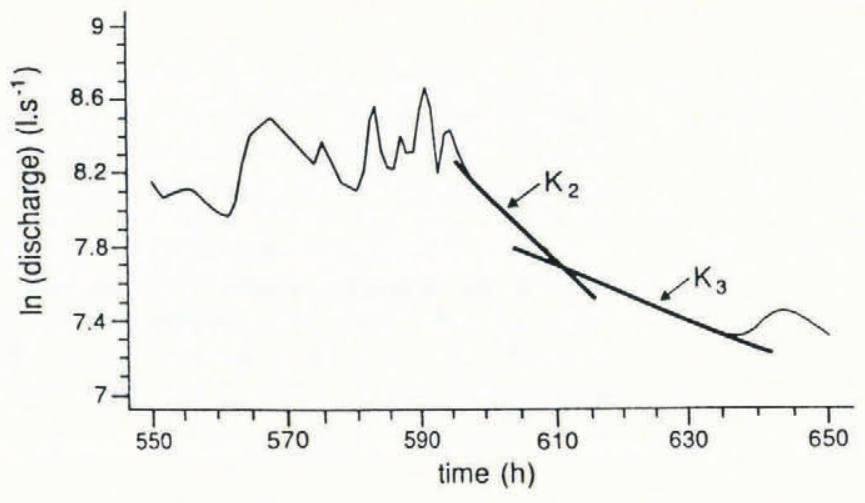

Fig. 1. Examples of flow recessions.

reservoir 2). The upper element, when it occurred, was labelled reservoir 1 and slower recessions, when they occurred, were labelled reservoirs 3 and 4 in sequence according to the number of breaks of slope identified. On a few occasions during periods of very high ablation, recession of reservoir 1 was not complete before the commencement of the next diurnal hydrograph rise, so that no reservoir 2 elements appeared in the recession. The 1989 discharge record yielded 60 recessions, some of which contained breaks of slope and thus more than one linear component. The $K$ value was estimated for all linear components of recessions, yielding 38 estimates of $K$ for a "fast" reservoir (i.e. $K 1$; nine of these did not give way to a second slower recession before the commencement of the next hydrograph rise), 51 estimates of $K$ for a "medium" reservoir (i.e. $K 2$ ) and six estimates of $K$ for a "slow" reservoir (i.e. K3). Analysis of the prolonged recessions from 10 years of data yielded 11 estimates of $K 1,23$ estimates of $K 2,23$ values of $K 3$ and 13 values of $K$ for a "very slow" reservoir (i.e. K4). Examples of linear recessions are presented in Figure 1.

The two data sets were combined to provide an aggregated set in which all four reservoirs were presented by a reasonable sample of $K$ estimates (49 estimates for $K 1,74$ for $K 2,29$ for $K 3$ and 13 for $K 4$ ). Figure 2 presents frequency histograms for all of the $K$ values and for $K 1$ to $\kappa 4$ separately. Whilst the values of $K 4$ produce a very broad-frequency histogram, the values for the other three reservoirs do not show a great deal of internal variation. The mean values are $13,29,72$ and $203 \mathrm{~h}$, for $K 1$ to $K 4$, respectively.

Although there is limited internal variation in the $K$ values for at least three of the four reservoirs identified, Figure 3 illustrates that there are identifiable and 
AlI K values

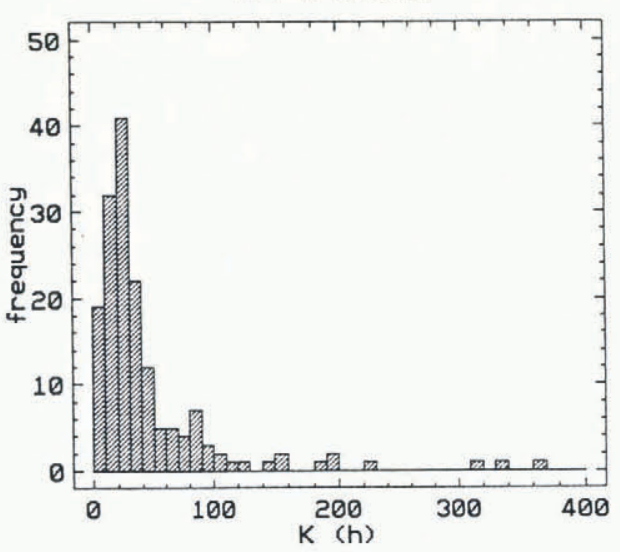

$\mathrm{K} 1$

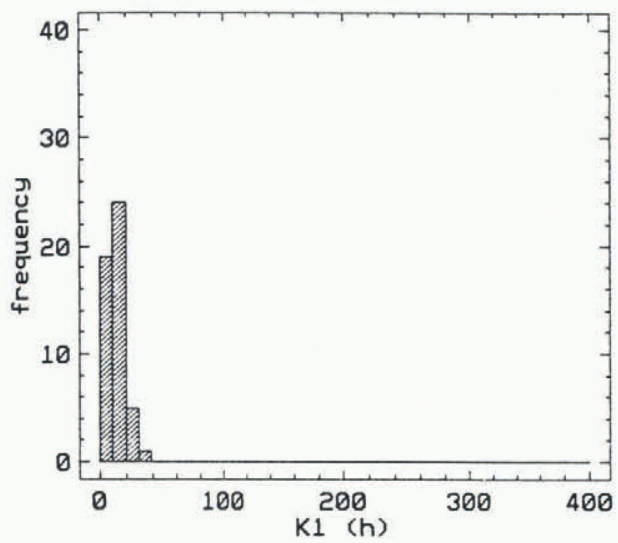

K3

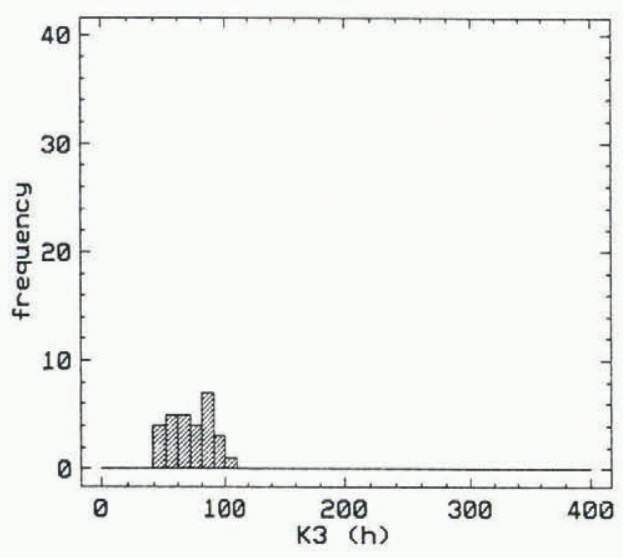

K2

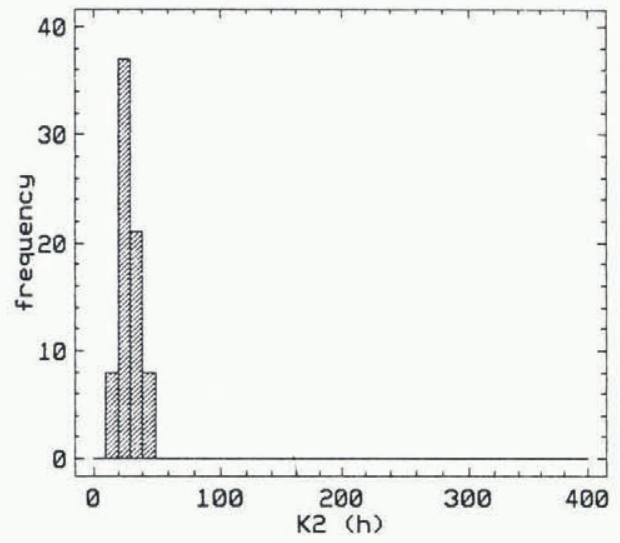

K4

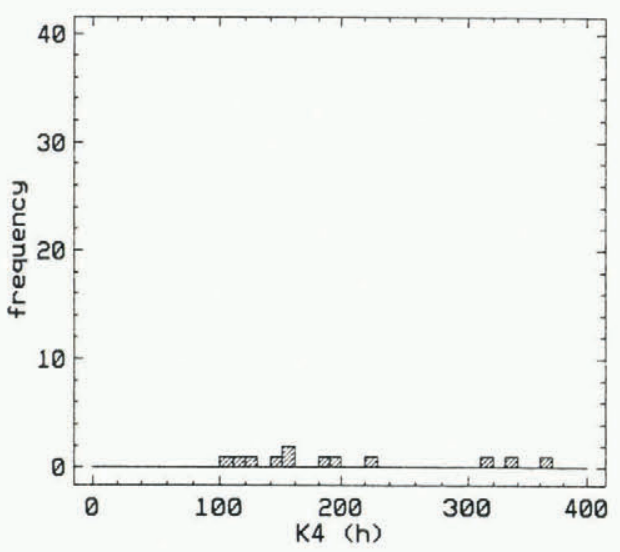

Fig. 2. Frequency histograms of reservoir coefficients $K, K 1, K 2, K 3$ and $K 4$.

consistent patterns within the variation that does exist. Figure 3 relates the values of $K 1$ to $K 4$ to the initial discharge at the commencement of the recession from which $K$ was estimated (Fig. $3 a$ ) and the timing of the recession within the ablation season (Fig. 3b). Figure $3 \mathrm{~b}$ shows a decline in the within-group values of $K 1$ to $K 4$ as the ablation season progresses, with some evidence of an increase in value towards the end of the season. The lowest values for $K$ appear to occur around day 80 (i.e. 19 August). The precise timing must be heavily influenced by the fact that much of the data set is derived from a single ablation season (1989), but the general trend of reduction and increase of $K$ for any specific reservoir is consistent with the changing efficiency of the glacierdrainage system, which transports water from the glacier reservoirs, through a typical ablation season (Röthlis- berger and Lang, 1987). It is also interesting to note that in 1989 diurnal-discharge cycles did not commence until $11 \mathrm{June}$ and that breaks of slope on the diurnal-discharge recession flows, indicating the operation of a "fast" reservoir, did not commence until 2 July. Figure 3a shows that the value of $K$ is also dependent on discharge at the commencement of the recession from which $K$ is estimated. This suggests that our four "linear" reservoirs are in fact "non-linear" to some degree and that this nonlinearity is discharge-dependent.

Since the patterns displayed in Figure 3 suggest nonlinearity in the response of the four reservoirs, it is tempting to ask whether there is a clearly definable relationship between $K$ and discharge for each reservoir. Figure 4 and Table 1 show linear (Fig. 4b) and non-linear (Fig. 4a) relationships estimated between $K$ and discharge 

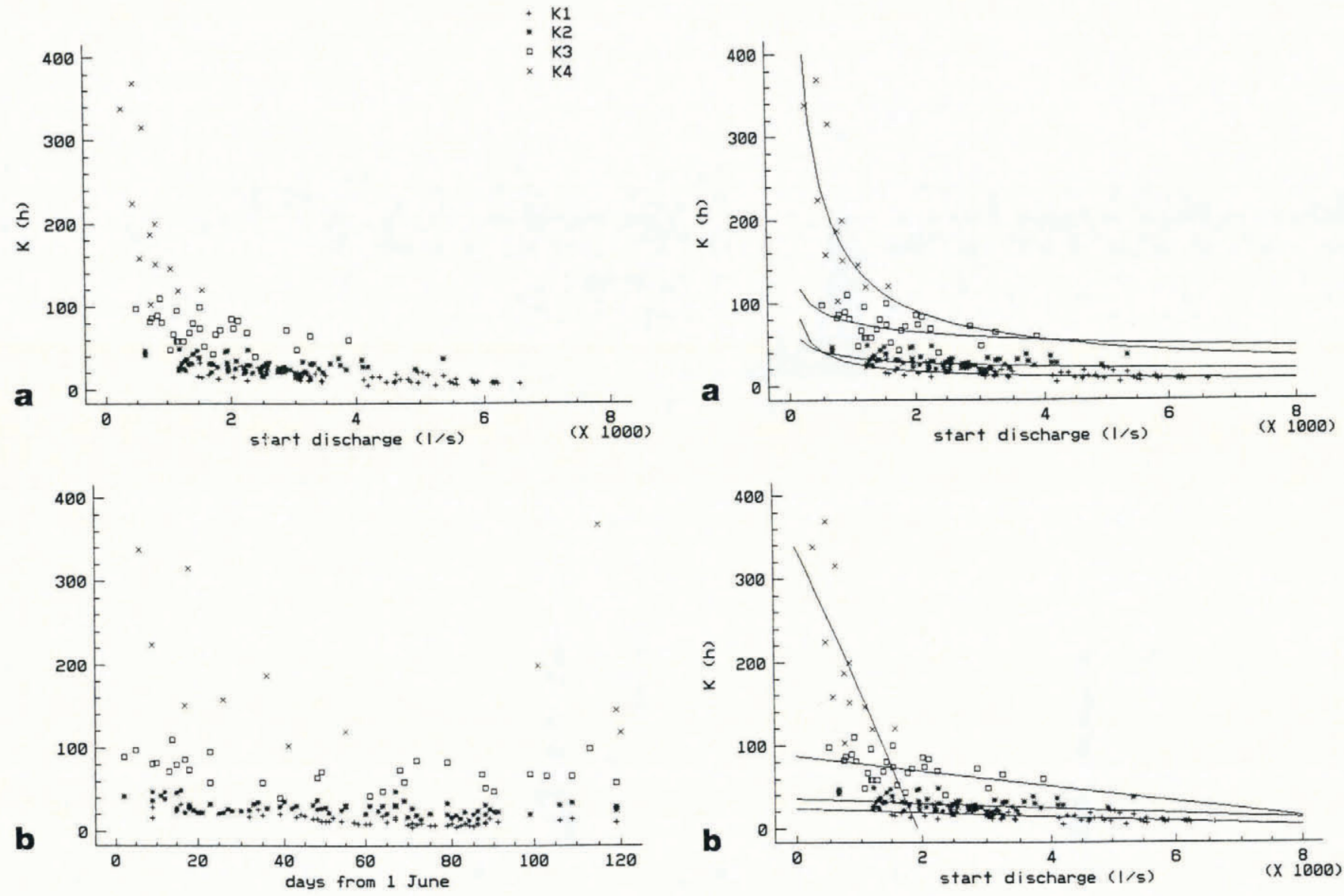

Fig. 3. Scatter plots of $K$ against: a. Discharge at the commencement of flow recession. $b$. Day number.

for each of the reservoirs by regression analysis. Although the explanation for $K$ provided by each of the regression models is not particularly high, all of the models illustrate that a significant pattern exists in the sample data. This implies that none of the reservoirs is truly linear (i.e. none possesses a single, constant value of $K$ ). Since $K$ is apparently dependent to some degree on discharge within each of the reservoirs, it is interesting to test the hypothesis that the recession-curve analysis supports the existence of only a single, non-linear reservoir, rather than four linear or non-linear reservoirs. Figure 5 plots a curved relationship between $K$ and discharge and associated 95 and $99 \%$ confidence limits that were estimated by regression analysis. Table 1 shows that this estimated relationship has a relatively high coefficient of determination and that the standard error of the estimate, although larger than the individual values for the four reservoir models, does not represent an unacceptably large increase.

\section{A FIRST APPROXIMATION TO FLOW SEPAR- ATION}

So far, the analysis and discussion has concentrated upon aggregate $K$ values estimated from linear recessions on semi-logarithmic plots of total discharge time series. However, in many cases, adjacent linear recessions of different slope occur, where it is possible to extend the lower slope element beneath the upper and so achieve a

Fig. 4. a. Non-linear; b. Linear relationships estimated between $K 1-K 4$ and discharge at the commencement of flow recession.

first approximation for a separation of the flow from the faster reservoir. As previously noted, if the reservoirs do not meet the conditions required for application of Equation (1), then the estimate of the separated $K$ value will be in error. In particular, the likelihood of recession with no input to a reservoir decreases if the reservoirs are linked in series rather than operating in parallel. Errors are likely to be greatest when estimating $K$ values for the most rapidly responding reservoirs. Given these cautions, analysis of multiple recessions yielded 45,20 and 11

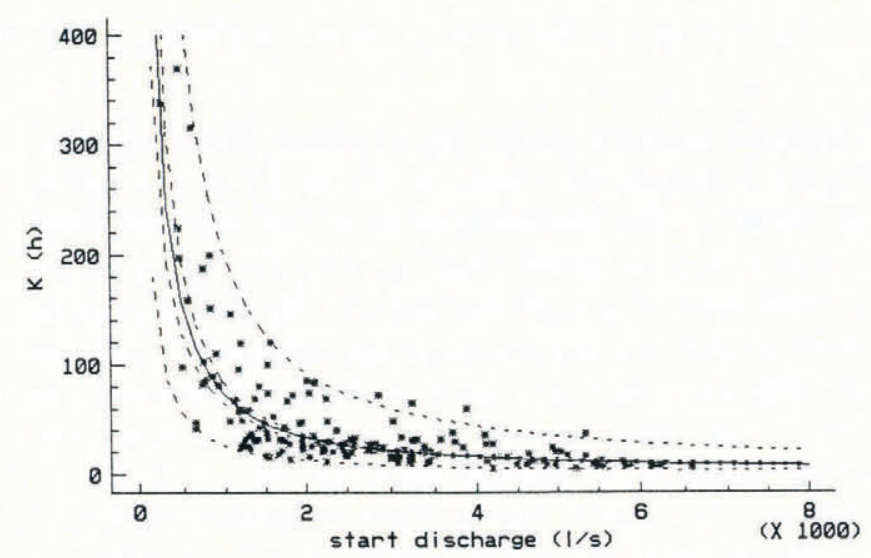

Fig. 5. Relationship between $\ln K$ and $\ln$ discharge at commencement of recession. The relationship was estimated using linear regression analysis, and the $95 \%$ and $99 \%$ confidence limits are shown. 
Table 1. Estimated relationships between aggregated reservoir coefficients and discharge at the start of flow recession

$\begin{array}{ccccccc}\text { Independent } & \text { Dependent } & a & & b & R^{2} & \begin{array}{c}\text { Standard } \\ \text { variable }\end{array} \\ \text { variable } & & & & & \begin{array}{c}\text { error of } \\ \text { estimate }\end{array}\end{array}$

$\begin{array}{llrrrr}\text { Discharge } & K 1 & 24.02 & -0.003 & 0.391 & 4.9 \\ & K 2 & 35.89 & -0.003 & 0.105 & 8.1 \\ & K 3 & 87.03 & -0.009 & 0.177 & 16.2 \\ & K 4 & 338.27 & -0.176 & 0.479 & 68.9 \\ \text { ln discharge } & \ln K 1 & 7.418 & -0.595 & 0.389 & 0.34 \\ & \ln K 2 & 5.424 & -0.273 & 0.153 & 0.27 \\ & \ln K 3 & 5.934 & -0.231 & 0.199 & 0.23 \\ & \ln K 4 & 9.706 & -0.684 & 0.575 & 0.29 \\ & & & & & \\ & \ln K & 11.717 & -1.078 & 0.661 & 0.51\end{array}$

Discharge is in $1 \mathrm{~s}^{-1}$.

$K, K 1, K 2, K 3$ and $K 4$ are expressed in hours.

All slope coefficients $(b)$ are significantly different from zero $(P<0.05)$.
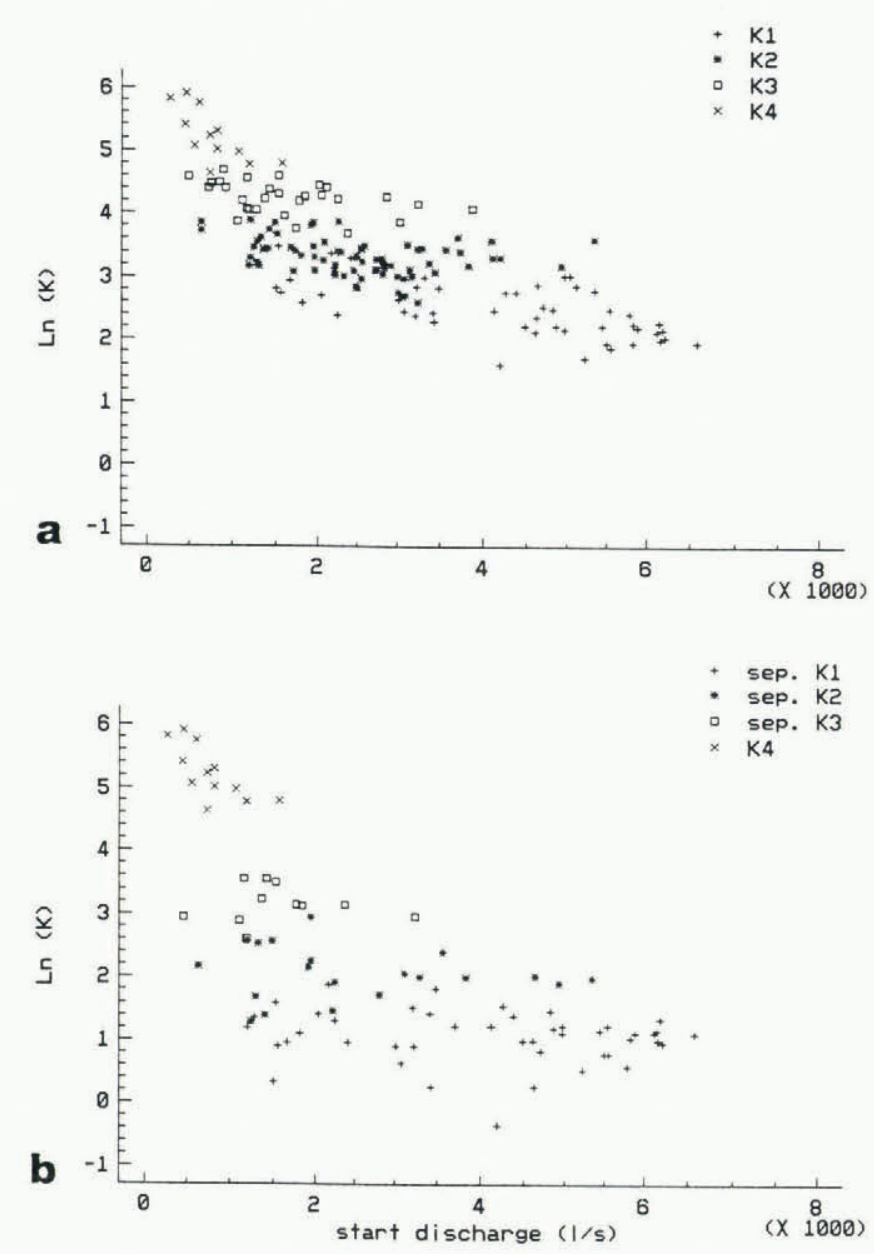

Fig. 6. a. Aggregated $K$ values; $b$. Separated $K$ values plotted against bulk discharge at the commencement of the recession. separated estimates for $K 1, K 2$ and $K 3$. The respective average values were 3,8 and 24 h. Figure 6 illustrates that the relationship between separated $K$ and total discharge at the commencement of the recession (Fig. 6b) is less apparent than for the aggregated $K$ values (Fig. 6a). Indeed, the results of regression analysis applied to both the raw and log-transformed values of $K 1$ to $K 3$ and the discharge at the start of the recession show that there is no significant relationship $(P>0.05)$ between the reservoir coefficients and bulk discharge for any of the three reservoirs. However, the temporal pattern of declining $K$ values in all reservoirs up to at least day 80 remains, although in a less marked form, for separated (Fig. 7b) than for aggregated (Fig. 7a) $K$ values. The apparent seasonal adjustment in the separated $K$ values may be an artifact of the crude and suspect method of reservoir separation that has been applied. In reality, changes in the size, location or degree of connectivity of the reservoirs through the ablation season can all contribute to mismatch between the simple linear reservoir model assumed in the present analysis and actual processes occurring in the glacier basin. The level of connectivity between reservoirs is likely to change dramatically over the ablation season. For example, it is conceivable that two reservoirs might operate in an essentially parallel way early in the ablation season, but that they could then become serially connected later in the season, as the snow line recedes up the glacier and supraglacial drainage, for
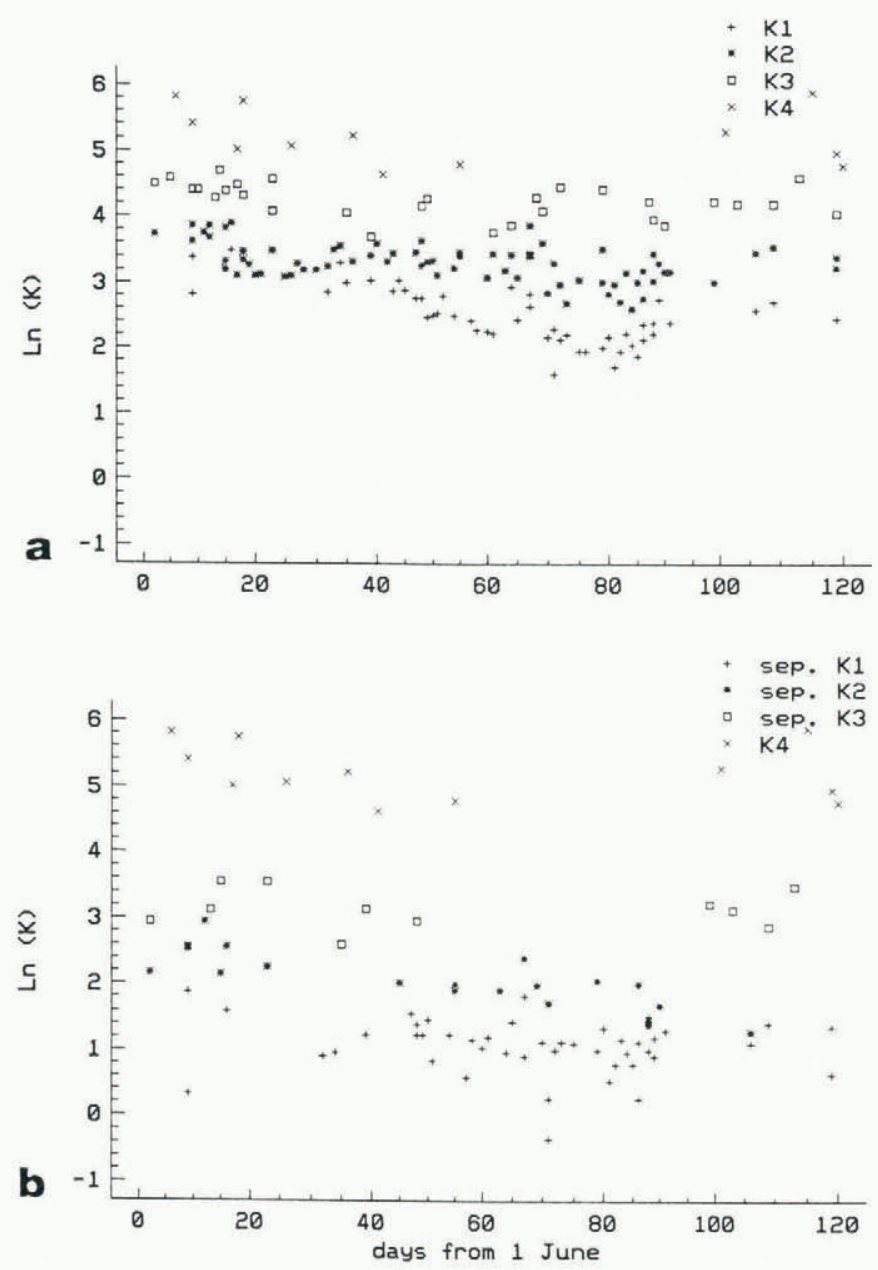

Fig. 7. a. Aggregated $K$ values; $b$. Separated $K$ values plotted against day number. 
example, is more readily able to take advantage of moulins and crevasses to reach the glacier bed.

\section{HOW MANY RESERVOIRS?}

This paper has only included a brief exploration of recession-curve analysis but it has provided some conclusions and some questions that require testing using complementary data sets.

The main conclusions are first, that truly linear reservoirs are not supported by recession-flow analysis, but secondly such an analysis does aid in the general understanding of glacier hydrology. Discussion of the processes underlying the seasonal pattern of variation in the $K$ values and the fact that some of the defined reservoirs do not operate at the commencement of the ablation season have deliberately been left to a subsequent paper when the full range of data sets collected in the integrated study of Haut Glacier d'Arolla basin can be jointly presented. Any interpretation at this stage would really be speculation, although it is very tempting to assign locations and physical meanings to the four reservoirs on the basis of the data presented here.

The practical questions that remain relate to the number of reservoirs that we can usefully identify in attempting to model the hydrology of the glacier rather than to understand the internal processes governing that hydrology. In a research context, it may prove necessary to represent the glacier hydrology by several linear or non-linear reservoirs. However, in the context of operational hydrological modelling, it appears that this glacier basin can probably be quite effectively represented by a single non-linear reservoir.

\section{ACKNOWLEDGEMENTS}

M. Sharp and anonymous referees provided some very constructive criticism which led to major improvements in the manuscript. Grande Dixence S.A. are very gratefully acknowledged for the provision of hourly discharge data. This paper reports on a component of an integrated research programme in the basin of Haut Glacier d'Arolla which was supported by U.K. NERC research grant GR3/7004.

\section{REFERENCES}

Baker, D., H. Escher-Vetter, H. Moser, H. Oerter and O. Reinwarth. 1982. A glacier discharge model based on results from field studies of energy balance, water storage and flow. International Association of Hydrological Sciences Publication 138 (Symposium at Exeter 1982 Hydrological Aspects of Alpine and High-Mountain Areas), 103-112.

Bako, M. D. and A. Owoade. 1988. Field application of a numerical method for the derivation of baseflow recession constant. Hydrological Processes, 2, 331-336.

Barnes, B.S. 1939. The structure of discharge recession curves. Trans. Am. Geophys. Union, 20, 721-725.

Collins, D. N. 1982. Water storage in an Alpine glacier. International Association of Hydrological Sciences Publication 138 (Symposium at Exeter 1982 - Hydrological Aspects of Alpine and High-Mountain Areas), 113-122.

Lundquist, D. 1982. Modelling runoff from a glacierized basin. International Association of Hydrological Sciences Publication 138 (Symposium at Exeter 1982 - Hydrological Aspects of Alpine and High-Mountain Areas), 131136.

Nathan, R.J. and T.A. McMahon. 1990. Evaluation of automated techniques for baseflow and recession analyses. Water Resour. Res., 26, 1465-1474.

Oerter, H., D. Baker, H. Moser and O. Reinwarth. 1981. Glacial-hydrological investigations at the Vernagtferner glacier as a basis for a discharge model. Nord. Hydrol., 12, 335-348.

Röthlisberger, H. and H. Lang. 1987. Glacial hydrology. In Gurnell, A. M. and M.J. Clark, eds. Glacio-fluvial sediment transfer: an alpine perspective. Chichester, etc., John Wiley and Sons, 207-284.

The accuracy of references in the text and in this list is the responsibility of the author, to whom queries should be addressed. 